\title{
Condomínio especializado para pessoa idosa: morar ou não morar? Eis a questão! Um estudo de caso em Viçosa-MG/ Brasil.
}

\author{
Specialized condominium for elderly person: living or not dying? That is the question! \\ A case study in Viçosa-MG/Brazil.
}

\author{
Cassia Figueiredo Rossi Dardengo* \\ Simone Caldas Tavares Mafra**
}

\begin{abstract}
Resumo
Dados do IBGE revelam que o Brasil está passando por uma inversão em sua pirâmide etária e juntamente com o envelhecimento da população o país experimenta, também, o aumento da expectativa de vida. Essa nova realidade exige atenção especial do poder público e da sociedade para atender às novas demandas daqueles que estão envelhecendo. Assim, buscou-se conhecer como pensam os idosos de Viçosa a respeito de morar em um condomínio especialmente projetado eles. Para tanto, realizou-se uma pesquisa qualitativa, descritiva e exploratória, com os participantes das atividades do "Clube da Vovó" e do "Programa Municipal da Terceira Idade-PMTI", utilizando-se da entrevista semiestruturada, analisadas com o auxílio do software IRAMUTEQ. O significado de qualidade de vida, conforme a Nuvem de Palavras e a análise estatística remeteram-se, principalmente, às palavras "saúde física", "saúde mental" e "independência", demonstrando que os idosos se preocupam com a moradia e a qualidade de vida, onde estar bem física e mentalmente auxilia no processo de envelhecimento. Pode-se concluir que o significado do envelhecimento e da velhice para os entrevistados tem relação direta com o seu contexto de vida e experiências, destacando-se por aspectos ligados ao protagonismo, à temporalidade e aos desafios do dia-a-dia.
\end{abstract}

Palavras-chave: Moradia. Condomínio. Idosos. Velhice. Envelhecimento.

\begin{abstract}
IBGE data reveal that Brazil is undergoing a reversal in its age pyramid and, together with the aging of the population; the country also experiences an increase in life expectancy. This new reality demands special attention from the public power and society to meet the new demands of those who are aging. Thus, it was sought to know how the elderly of Viçosa think about living in a condominium specially designed them. For that, a qualitative, descriptive and exploratory research was carried out with the participants of the activities of the "grandma's club" and the "Municipal Program of the Elderly - PMTI", using the semi-structured interview, analyzed with the aid the IRAMUTEQ software. The meaning of quality of life, according to the Word Cloud and statistical analysis, was mainly related to the words "physical health", "mental health" and "independence", demonstrating that the elderly care a bout housing and quality of life, where being physically and mentally helps in the aging process. It can be
\end{abstract}

\footnotetext{
* Engenheira Civil na Universidade Federal de Viçosa - UFV. Especialista em Planejamento Urbano e pósgraduação em Gestão Estratégica. Mestre em Engenharia da Construção pela Universidade Federal de Viçosa. Doutora em Economia Doméstica pela UFV, Área de concentração "Família e Sociedade". E-mail: cassia.dardengo@ufv.br.

** Professora Titular da Universidade Federal de Viçosa de Minas Gerais, Professora do Programa de Pósgraduação em Economia Doméstica da Universidade Federal de Viçosa de Minas Gerais. Doutora em Engenharia de Produção pela Universidade Federal de Santa Catarina. Pós doutorado em Minority Aging pela University of Texas Medical Branch, Texas, EUA. Universidade Federal de Viçosa, Centro de Ciências Humanas Letras e Artes, Departamento de Economia Doméstica. Campus Universitário, CEP: 36570-900, Viçosa, MG, Brasil. E-mail: sctmafra@ufv.br.
} 
concluded that the meaning of aging and old age for the interviewees is directly related to their context of life and experiences, emphasizing aspects related to protagonism, temporality and the challenges of everyday life.

Keywords: Housing. Condominium. Elderly. Old age. Aging.

\section{Introdução}

Diversos países do mundo, incluindo o Brasil, tem se defrontado com uma nova perspectiva populacional: o envelhecimento. Segundo estimativas da Organização das Nações Unidas (2003), o número de pessoas com idade acima de 60 anos irá triplicar em 50 anos, totalizando cerca de 2 bilhões de idosos. Segundo dados de Mellis (2018), a população idosa brasileira deverá duplicar até o ano de 2042, na comparação com os números de 2017. De acordo com os dados levantados, o Brasil possuía 28 milhões de idosos no ano de 2016, cerca de 13,5\% do total da população. Em dez anos, chegará a 38,5 milhões, ou seja 17,4\% do total de pessoas. Em 2042, a projeção do IBGE é de que a população brasileira alcance 232,5 milhões de habitantes. Destes, 57 milhões serão idosos (24,5\%).

Segundo Debert e Simões (2006), dentre os fatores que influenciaram no aumento da expectativa de vida dos últimos anos, estão a diminuição da fecundidade nas últimas décadas, a redução da mortalidade infantil, melhorias no saneamento básico, controle de doenças, dentre outros. Alguns fatores ligados a essas mudanças estão diretamente atrelados às famílias, através de alterações nos seus papéis sociais, redução nos números de filhos, migração rural-urbana, que modificam as funções tradicionais da família como educadora de crianças e de cuidadora dos mais velhos.

Embora se verifique que exista uma forte valorização da família no processo de envelhecimento, o número de idosos que decidem morar sozinhos tem aumentado significativamente nas últimas décadas (IBGE, 2013). Goldenberg (2015) destaca que a ideia de solidão e abandono pelo fato dos idosos morarem sozinhos vem sendo modificada, assim como também uma mudança no significado da moradia, onde antes era percebido como um lugar para dormir e comer, passou a ser um espaço de lazer, prazer e criatividade. Assim, podese dizer que "morar sozinho, em diferentes fases da vida, tornou-se uma opção legítima, especialmente para uma geração que está inventando uma nova forma de envelhecer, mais bela, prazerosa e significativa" (ARIGONI; CECCON; DAMAZIO, 2016, p. 2978).

Pesquisas recentes destacam uma redução do número de pessoas idosas morando 
com filhos nos Estados Unidos e na Europa (PRADO; PERRACINI, 2011), como por exemplo, Holanda, Inglaterra e Portugal. No Brasil, segundo dados do IBGE (2013) essa tendência aumentou cerca de 3 vezes em um período de 20 anos, entre os anos 1992 e 2012, passando de quase 1 milhão de idosos para cerca de 4 milhões de idosos residindo sozinhos. Segundo dados da Pesquisa Nacional por Amostra em Domicílios (PNAD), em 1992, 1,17 milhão de idosos moravam sozinhos, em 2012 esse número triplicou, chegando a cerca de 3,7 milhões (IBGE, 2012), conforme nota-se na figura 1. Assim, pode-se constatar que esses idosos estão buscando autonomia e independência, características de uma velhice bem-sucedida.

Figura 1 - Crescimento do número de idosos morando sozinhos

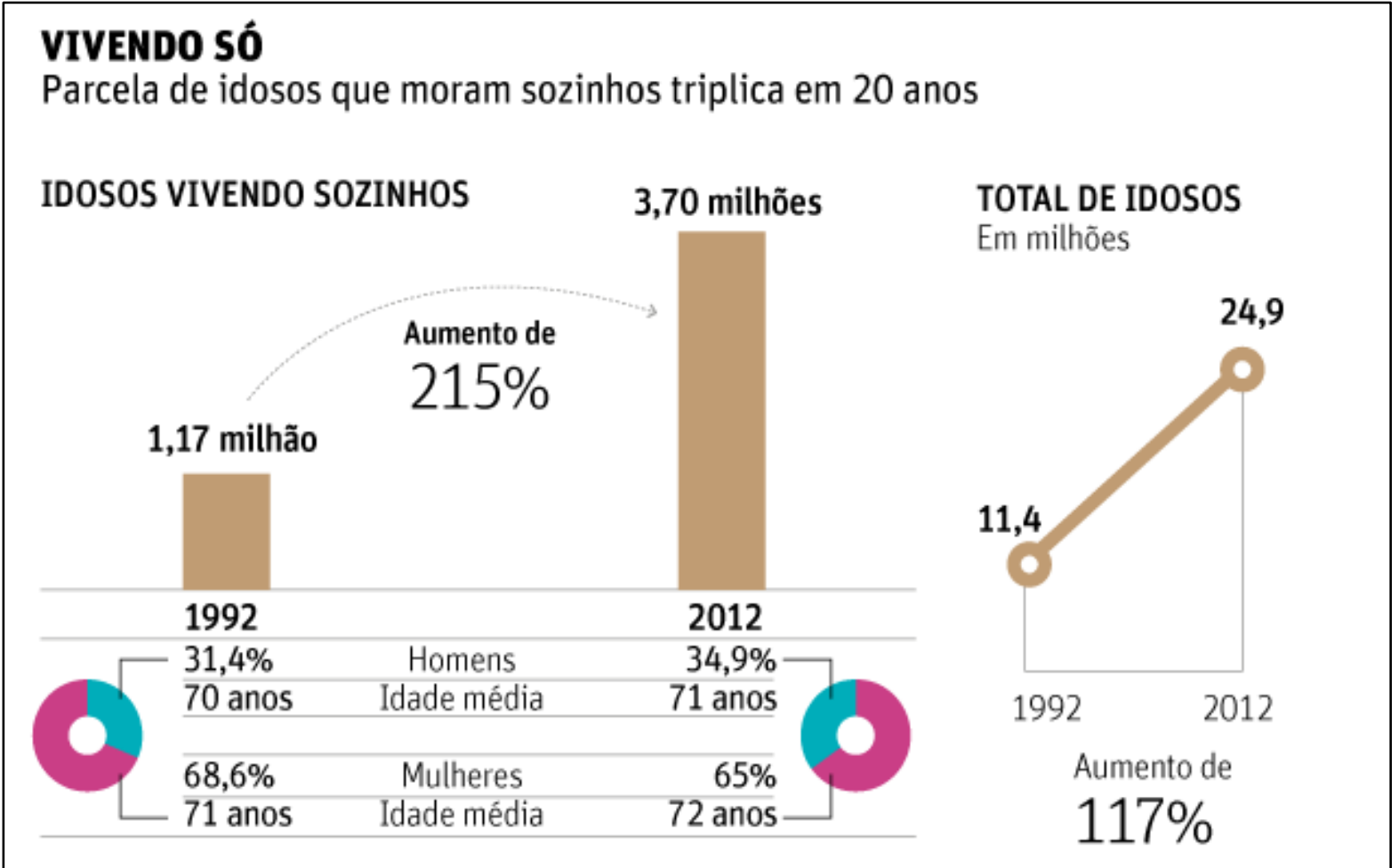

Fonte: IBGE (2015).

Conforme dados do IBGE (2015) verifica-se que o déficit habitacional no Brasil era de aproximadamente 6,5 milhões de domicílios, dos quais 5,572 milhões $(87,7 \%)$, estavam localizados nas áreas urbanas e 783 mil unidades na área rural. Do total do déficit habitacional em 2015, 39\% localizava-se na região Sudeste, correspondente a 2,482 milhões de unidades. Ainda segundo dados do IBGE (2015), Minas Gerais é o segundo estado com maior déficit, com 575 mil unidades. No entanto, não existem dados específicos em relação à demanda por habitação voltada aos idosos. 
Verifica-se que, apesar dos programas do Governo Federal, como por exemplo, o "Minha Casa, Minha Vida", lançado em março de 2009 e que atingiu seu ápice nos anos de 2011 a 2014, visando reduzir o déficit habitacional do país, os Programas Habitacionais para a população idosa são escassos, visto que demandam grande disponibilidade de recursos não apenas construtivos, mas também na área da saúde, assistência social dentre outras áreas (SCHUSSEL, 2012). Assim, como forma de atender a esta demanda crescente, surgem alguns programas de moradias para se buscar amenizar essa deficiência, em sua grande maioria, através de parcerias privadas, mas que grande parte da população não tem acesso visto os altos investimentos mensais.

Desta forma, em virtude da insuficiência de programas voltados para moradia da população idosa, assim como a dificuldade em se obter financiamentos habitacionais para esse extrato populacional, destaca-se a importância da moradia para essa população.

Constata-se que a moradia está diretamente ligada à saúde, onde, de acordo com o conceito universal sobre saúde, envolve o bem-estar físico, mental e social, tendo a moradia um papel fundamental na manutenção da autonomia e independência da pessoa idosa. De acordo com Oswald e Wahl (2004), o idoso prefere envelhecer em sua casa e junto aos seus objetos pessoais. As escolhas por envelhecer em casa estão ligadas ao sentimento de apego ao lugar, segurança, familiaridade e laços com a comunidade ou vizinhança.

Ely e Dorneles (2006) destacaram que o processo de envelhecimento cria necessidades diferenciadas para os idosos, devendo este processo ser pesquisado com o objetivo de se criar espaços adequados. Sâmia (2008) enfatizou que a adequação do ambiente doméstico, além da organização espacial, reduz os riscos de quedas garantindo à pessoa idosa o "deslocamento dentro de seu próprio ambiente".

Abordar essa temática é de grande importância para a solução dos problemas relacionados ao direito à moradia da população idosa, conforme capítulo II, art. 60 da Constituição Federal, assim como para a reflexão relacionada à garantia de um envelhecimento saudável.

Nesse cenário, este estudo teve como objetivo avaliar a aceitabilidade de um grupo de idosos quanto à alternativa habitacional de moradia em condomínios especializados, adaptados à população idosa, a partir de um estudo de caso na cidade de Viçosa-MG, visto que a moradia adequada contribui para um envelhecimento bem- -sucedido, com autonomia e independência, proporcionando uma melhor qualidade de vida. 


\section{Revisão de Literatura}

Segundo o artigo 6o da Constituição Federal (1988), a Declaração Universal dos Direitos Humanos (1948) e o Pacto Internacional dos Direitos Sociais, Econômicos e Culturais (1966), é dever do Estado de prover, por meio de políticas públicas, a concessão do direito à moradia (BRASIL, 1992).

A Organização das Nações Unidas refere-se à moradia digna no "Comentário Geral, do Comitê dos Direitos Econômicos, Sociais e Culturais das Nações Unidas para o Controle dos Tratados em Matéria de Direitos Humanos", também na Comissão sobre Assentamentos Humanos, conceituando a moradia digna e adequada, caracterizando atributos objetivos e subjetivos que contribuem para sua qualificação. Nessa perspectiva a moradia é considerada como sendo um "componente do direito a um padrão de vida adequado" (BRASIL, 2013 p. 10). Especifica-se também a prioridade de acesso aos grupos sociais discriminados e estigmatizados, como os idosos.

Ainda relacionado ao direito à moradia para a pessoa idosa, tem-se o Estatuto do Idoso - artigo 37 que destaca que: "o idoso tem direito à moradia digna, no seio da família natural ou substituta, desacompanhados de seus familiares, quando assim o desejar, ou ainda, em instituição pública ou privada" (BRASIL, 2003) instituindo a autonomia do idoso em relação a formas de amparo e moradia na velhice.

Neste cenário, a moradia digna e adequada torna-se um fator determinante de acesso à saúde, bem-estar, envelhecimento ativo e qualidade de vida, contemplando também a subjetividade dos seus moradores, para possibilitar a expressão e preservação da identidade, a diversidade racial e cultural (BRASIL, 2013, p. 20).

Conforme Oswald e Wahl (2004), o ambiente de moradia compreende um dos lugares mais importantes onde acontece o envelhecimento do indivíduo. Ainda no século passado, Lawton (1977) foi um dos primeiros pesquisadores a estudar as relações entre o envelhecimento humano e o ambiente de moradia, apresentando um modelo teórico conhecido como "modelo ecológico do envelhecimento", que estuda os aspectos que facilitam a adaptação ambiental dos idosos. Esses aspectos compreendem as capacidades individuais - sensação/percepção/cognição, e aquelas exercidas por onde vivem capacidades físicas e sociais (LAWTON, 1982).

Assim, ainda segundo Oswald e Wahl (2004), a pessoa idosa geralmente opta por envelhecer em casa, ao lado de objetos pessoais reunidos ao longo de sua existência. Essa 
preferência por envelhecer em casa está diretamente ligada aos aspectos de apego, segurança, familiaridade e laços com vizinhança. De acordo com dados do IBGE (2009), existe um grande número de idosos morando em domicílios unipessoais, cerca de $41,8 \%$ morando sozinhas. Dentre os principais motivos assinalados estão a preservação da liberdade, independência, autonomia e capacidade funcional.

Além da opção da pessoa idosa por envelhecer em casa e das atividades que realiza ao longo do dia e no lugar em que vive, o espaço físico da residência simboliza um aspecto da moradia que pode auxiliar ou prejudicar a execução das atividades da vida diária de forma independente. Ao mesmo tempo, sabe-se que barreiras arquitetônicas contribuem para segregar a pessoa idosa, comprometendo à participação na comunidade (WEBBER; PORTER; MENEC, 2010). Assim, segundo Gilleard, Hyde e Higgs (2007, p. 591), "envelhecer em um lugar familiar, com pessoas e rotinas familiares resulta num forte senso de satisfação e contentamento". Da mesma forma Paúl (2005) também destacou a importância do ambiente de moradia para os idosos, cuja satisfação com o lugar onde vivem está associada ao sentido de bem-estar.

Ainda hoje, nos Estados Unidos, evidencia-se um conceito, que teve origem na década de 1970, chamado de aging in place. Esta concepção destaca a percepção das alterações ocorridas durante o processo de envelhecimento em relação com o ambiente que rodeia o indivíduo, envolvendo a manutenção da vida no meio onde se vive (MARTIN et al., 2012). De acordo com Rosel (2003), o aging in place auxilia no entendimento dos vínculos existentes entre a pessoa idosa e os contextos onde estão inseridos, quer seja a moradia, vizinhança, comunidade e as redes sociais instituídas ao longo de sua vida.

Assim, o ambiente construído e adaptado para que o idoso possa morar com dignidade é essencial para a manutenção da autonomia e independência, permitindo uma melhor dinâmica para realização das tarefas, assim como nas atividades de vida diária (AVD). A moradia se torna eficiente quando os aspectos estruturais são adequados e constituídos por mecanismos que favoreçam a confiança, segurança e domínio do espaço de moradia.

Dessa forma, a moradia adquire funções que vão além da ideia de abrigo. Csikszentmihalyi e Rochberg-Halton (1981, p. 9) citaram que "a casa é o lugar de memórias, experiências e sonhos de cada pessoa. E eles são inseparáveis dos objetos que compõem seu ambiente". Esses autores sintetizam que: 
A casa é muito mais do que um abrigo; é um mundo no qual uma pessoa pode criar um ambiente material que incorpora o que ele ou ela considera significativo. Sendo assim, a casa torna-se o sinal mais poderoso da identidade de seu morador (CSIKSZENTMIHALYI; ROCHBERG-HALTON, 1981, p. 123).

Conforme Bestetti (2006), tendo em vista as alterações físicas decorrentes do processo de envelhecimento, o projeto de moradias adaptadas para a pessoa idosa deve priorizar os aspectos relacionados a: acessos (visibilidade e distância); circulação (tipo e tamanho); dimensões (ambientes e equipamentos); barreiras arquitetônicas (escadas, desníveis, sistema de segurança); condições ambientais (iluminação, ventilação e acústica); revestimento (textura, temperatura); manutenção (facilidade de limpeza e acessibilidade); aspectos psicodinâmicos (cor e tamanho); aspectos tecnológicos (sistema de comunicação, segurança contra incêndio e controle de insolação) e outros aspectos (campainhas de alerta visual, instalações para computadores e luminárias de emergência).

Assim, os condomínios para a pessoa idosa despontam como uma modalidade habitacional constituindo-se em garantia do direito à moradia, de modo especial para a parcela da população mais carente. Diferentemente das Instituições de Longa Permanência para Idosos (ILPIs) os moradores dos condomínios exercem as atividades de vida diária (AVD) com independência e autonomia. É uma tipologia habitacional relativamente recente no Brasil, tendo surgido nos países desenvolvidos, na década de 1950. Esse tipo de organização cria espaços comuns de integração, atenuando a sensação de falta de perspectiva de vida para os envolvidos (MUELLER et al., 2004; GREENFIELD; MARKS, 2004). As atividades externas e a prestação de serviços de saúde, além de permitirem a expressão subjetiva das pessoas (DEBERT, 1997; LIMA, 2001), são formas de socialização e convivência grupal (ARANHA, 2003; TAMAI, 2003).

A principal característica dos condomínios especializados não é somente a questão da moradia, sendo bem mais amplo seu espectro. O que se pretende é propiciar à população idosa a inserção na vida da comunidade, com acesso aos diversos serviços e equipamentos públicos, revestindo-se em serviço de natureza pública.

No Brasil, já existem diversos condomínios para a pessoa idosa. Em João Pessoa, Campina Grande e Cajazeiras, na Paraíba, existe o condomínio “Cidade Madura”. É uma iniciativa do Governo estadual, sendo destinado aos idosos de baixa renda. "Os condomínios oferecem postos de saúde, academias ao ar livre, hortas comunitárias, pistas de caminhada, centros de convivência com salão, salas de aula, de TV e de fisioterapia, copa, banheiros 
acessíveis e até redário" (FREITAS, 2019).

No estado de São Paulo também existem diversos programas deste tipo. São José do Rio Preto, Ribeirão Preto, Avaré e Mogi das Cruzes também contam com programas semelhantes, que tem como objetivo a proteção dos moradores, preservando sua autonomia. As moradias são projetadas conforme o conceito do Desenho Universal, que facilita o uso da moradia por qualquer pessoa com dificuldade de locomoção, seja temporária ou permanente. Dessa forma, todas as casas "possuem itens de acessibilidade, como barras de apoio, portas e corredores mais largos, rampas de acesso e pisos antiderrapantes" (SÃO PAULO, 2016).

\section{Metodologia}

Realizou-se um estudo exploratório, de abordagem qualitativa, utilizando-se como principal método de coleta de dados a entrevista semiestruturada com os idosos. O estudo foi realizado no Município de Viçosa-MG, na Zona da Mata Mineira, tendo como unidades de análise o "Programa Municipal da Terceira Idade-PMTI" e o "Clube da Vovó". O Município de Viçosa-MG pode ser considerado um local de investigação propício para o estudo do envelhecimento, visto que, conforme dados do Retrato Social municipal (CRUZ, 2014), no ano de $2013,17 \%$ da população era composta por pessoas idosas. Valor considerado significativo, uma vez que o percentual mineiro e brasileiro, nesta faixa etária, era de $11,8 \%$ e 10,8\% respectivamente, da população idosa, sendo a média do município superior a do estado e do país.

Utilizou-se, como forma de se responder a pesquisa aplicada, o estudo de caso apontado por Yin (2005, p. 32), “[...] o estudo de caso é uma investigação empírica que explora um fenômeno contemporâneo dentro de seu contexto da vida real”, que condiz quando "[...] as circunstâncias são complexas e podem mudar, quando as condições que dizem respeito não foram encontradas antes, quando as situações são altamente politizadas e onde existem muitos interessados" (LLEWELLYN; NORTHCOTT, 2007, p. 195). Martins (2008, p. 11) afirma que "o estudo de caso possibilita a penetração em uma realidade social, não conseguida plenamente por um levantamento amostral e avaliação exclusivamente quantitativa".

Escolheu-se como população da pesquisa os idosos participantes das atividades do "Programa Municipal da Terceira Idade-PMTI e do "Clube da Vovó". O Clube da Vovó é um programa filantrópico e social, que surgiu "como um local de encontro para bate-papo, diversão e descontração, para preenchimento do vazio existencial com brincadeiras, piadas, 
músicas, leitura de mensagens de otimismo e esperança, troca de experiências e conhecimentos" (ARRUDA, 2013). O Programa Municipal da Terceira Idade-PMTI é um serviço de Proteção Social Básica ligado ao Centro de Referência da Assistência Social (CRAS), cujo objetivo é fortalecer os vínculos familiares e comunitários, conforme orientações do Sistema Único da Assistência Social (SUAS), da Política Nacional da Assistência Social (PNAS) e Lei Orgânica da Assistência Social (CRAS, 2007). É também vinculado ao Departamento de Nutrição e Saúde da Universidade Federal de Viçosa - UFV, que visa a socialização da pessoa idosa, através de participação em eventos socioculturais de orientações nutricionais e de saúde.

A opção por estudar os idosos cadastrados nessas instituições decorreu do fato de que são organizações já consolidadas na cidade de Viçosa, possuindo cerca de 2.768 idosos. Desses, cerca de 400 idosos participam das diversas atividades oferecidas pelos programas (MAFRA, 2014). Tanto o PMTI quanto o Clube da Vovó são espaços que atendem em sua totalidade, pessoas idosas, onde são desenvolvidas atividades de lazer e outras de natureza filantrópica, promovendo o encontro e o bem-estar entre os participantes, o que revelou sua importância para o presente estudo.

O critério de inclusão para o estudo foi possuir idade igual ou superior a 60 anos e aceitar participar da pesquisa a partir da assinatura do Termo de Consentimento Livre e Esclarecido. O número exato de pessoas a fazer parte do estudo não foi definido a priori, esse número foi se ampliando a medida que o estudo de campo era desenvolvido. Assim, foram entrevistados 40 idosos no total, que compõem os sujeitos da pesquisa.

Os dados foram coletados entre agosto e setembro de 2018. O estudo foi aprovado pelo Comitê de Ética em Pesquisa com Seres Humanos (CEP), da Universidade Federal de Viçosa, sob o número CAAE no 87158218.4.0000.5153, e os participantes assinaram um Termo de Consentimento Livre e Esclarecido antes de sua inclusão na pesquisa.

As entrevistas aconteceram, na grande maioria das vezes, na casa número 07, da Vila Gianeti, situada no Campus da Universidade Federal de Viçosa-UFV, onde funcionam as atividades do PMTI, e também na residência de alguns idosos participantes do "Clube da Vovó". Os entrevistados responderam às perguntas: Você moraria em um condomínio adaptado para idosos que possuísse assistência médica e odontológica, equipamentos de lazer, academia, horta comunitária, centro de convivência, salas de TV e de refeições? O que você acha da ideia de um condomínio adaptado para a pessoa idosa? O que você considera 
importante ter nesse condomínio? O que você entende como qualidade de vida? O que você mais gosta de fazer e o que você não gosta de fazer? o que deveria ter nesse condomínio?

Após a transcrição das entrevistas, os dados coletados foram revisados, registrados e tabulados em uma planilha, procedendo-se às análises. Para apoiar a análise dos dados desta pesquisa, foi utilizado o software IRAMUTEQ (Interface de $R$ pour les Analyses Multidimensionnelles de Textes et de Questionnaires), que permitiu diferentes processamentos e análises estatísticas de textos produzidos. É ancorado no software R e na linguagem de programação python (CAMARGO; JUSTO, 2013), que no Brasil, começou a ser utilizado a partir de 2013. O IRAMUTEQ possibilita cinco tipos de análises: estatísticas textuais clássicas; pesquisa de especificidades de grupos; classificação hierárquica descendente; análises de similitude e nuvem de palavras.

Neste estudo, para o processamento de dados utilizou-se a Nuvem de Palavras. Assim, as palavras são agrupadas e organizadas graficamente de acordo com a sua frequência e associação entre elas, medida pela $X^{2}$, possibilitando a sua identificação, a partir de um único arquivo, denominado corpus, que reúne os textos originados pelas entrevistas. Assim, cada entrevista caracterizou um texto, e o conjunto desses textos constituiu o corpus de análise desta pesquisa.

A partir das palavras mais frequentes fornecidas nos segmentos de texto (são fragmentos de texto, na grande parte das vezes, de três linhas ou configurado pelo pesquisador, dimensionadas pelo próprio software em função do tamanho do corpus), foi realizada a análise lexical. Essa análise supera a separação entre a pesquisa quantitativa e qualitativa, visto que permite o emprego de cálculos estatísticos sobre dados qualitativos, os textos. O vocabulário foi identificado e quantificado em relação à frequência e, em alguns casos, também, em relação à sua posição no texto, ou seja, foi submetido à cálculos estatísticos para interpretação sendo uma das diferenças da análise de conteúdo, no qual o pesquisador interpreta para depois sistematizar.

\section{Resultados e discussões}

Os resultados foram organizados em dois blocos: Primeiro, a caracterização dos participantes e segundo a análise lexical através do método Nuvem de Palavras com as palavras evocadas pelos participantes. 


\section{Caracterização dos idosos participantes}

Quanto à caracterização dos participantes, identificou-se que, dos 40 entrevistados, 34 eram mulheres (85\%) e 6 homens (15\%), com idades entre 60 e 99 anos. Em relação ao estado conjugal, 6 eram solteiros (5 mulheres e 1 homem), 19 casados (4 homens e 15 mulheres), 11 idosas eram viúvas e 4 declararam que são separados (3 mulheres e 1 homem). Dos entrevistados, $22 \%$ têm curso superior, enquanto que $30 \%$ fizeram o ensino médio completo, outros $30 \%$ declararam possuir o ensino fundamental completo. Apenas 1 dos entrevistados declarou possuir o ensino médio incompleto, e outro afirmou possuir o curso superior incompleto. Outros 5 responderam apenas saber ler e escrever, sem terem frequentado a escola formal.

Do total entrevistado, 8 moravam sozinhos (20\%) superando os dados do estado de Minas Gerais. Segundo dados do IBGE (2010) em 2010, em Minas Gerais, essa proporção era de $13,7 \%$ do total de idosos. O crescimento no percentual de idosos que moram sozinhos na última década reforça não somente o envelhecimento populacional, mas também destaca a necessidade de se conhecer os determinantes dos arranjos familiares que incluem os idosos, assim como os fatores que contribuem para essa tendência de crescimento de idosos morando sozinhos. Esse crescimento de idosos morando de forma singular pode ser explicado, em parte, pela redução do número de filhos, aumento dos divórcios, mudanças de estilo de vida, melhora nas condições de saúde da população idosa e uma maior longevidade (CAMARGOS; MACHADO; RODRIGUES, 2007).

Os outros moravam com filhos, netos, irmãos, maridos/esposas. Apenas 2 ainda trabalhavam, enquanto que os outros eram aposentados e recebiam aposentadoria e/ou pensão. Dos entrevistados, 23 declararam ser brancos, 5 negros e outros 12 afirmaram ser pardos. Sobre a religião, 35 dos participantes se declararam católicos e 5 afirmaram ser evangélicos.

\section{Significado de qualidade de vida}

Para análise do significado da expressão "Qualidade de vida", dada pelos entrevistados, empregou-se o método de "nuvem de palavras" e do quiquadrado, que agrupa as palavras e as organiza graficamente em função da sua frequência, sendo as expressões: "saúde física", "saúde mental", "religião", "suporte familiar", "ser independente" e "trabalho/ocupação" as que tiveram maior frequência no corpus (ver figura 2). 
Como as expressões "saúde física" e "saúde mental", se destacaram mais do que todas a outras, procurou-se identificar o seu contexto nas entrevistas e o que foi sintetizado é que os idosos referiram-se a elas em situações interligadas. Eles destacaram que a qualidade de vida está diretamente ligada a possuir uma boa saúde física e mental, relacionada ao amparo familiar, religião, prática de atividades físicas e uma boa moradia. Verifica-se que na figura 2 as palavras são posicionadas pelas associações entre si, de forma que as que ocorrem com mais frequência e maior associação aparecem maiores que as outras, demonstrando, assim, o destaque no corpus de análise da pesquisa.

Figura 2 - Nuvem de palavras dos termos evocados como qualidade de vida

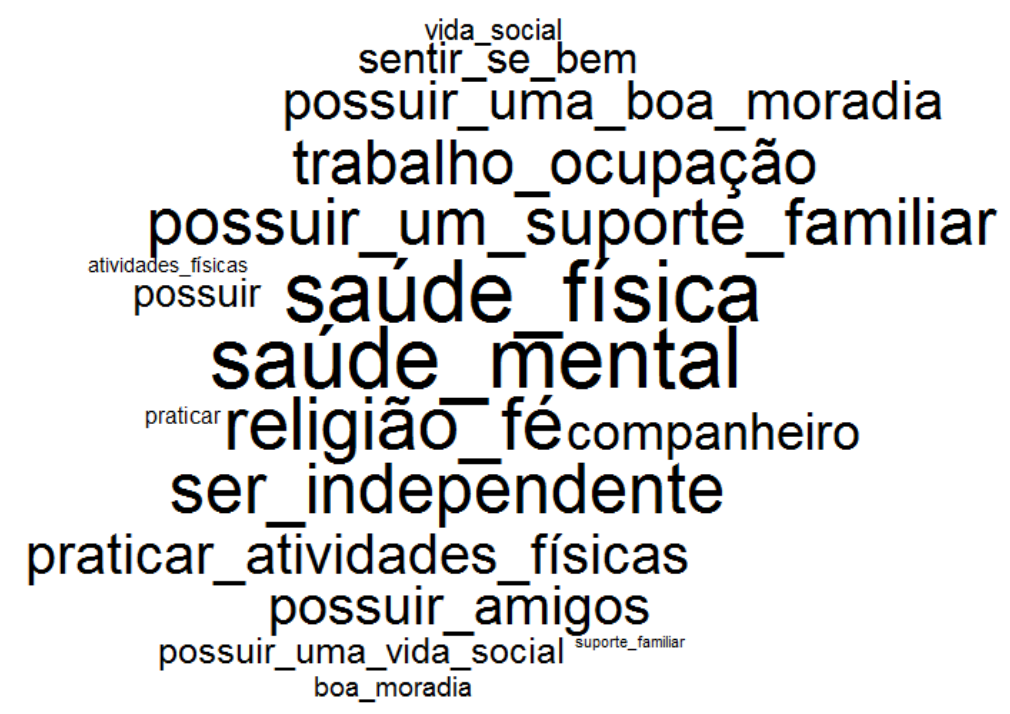

Fonte: Dados da Pesquisa, 2018.

De modo geral, pode-se dizer que, para os idosos, a qualidade de vida é um conceito subjetivo, onde cada um destaca o que é mais relevante para o seu bem-estar. Segundo os entrevistados, para que se obtenha uma boa qualidade de vida neste período vivido, é importante considerar alguns fatores, tais como: bem-estar físico e mental, nível de independência, praticar atividades físicas, possuir uma rede de relações sociais e familiares, ambiente de trabalho e lazer, religiosidade, dentre outros. De forma geral, entende-se que envelhecer com qualidade de vida significa estar satisfeito com a vida atual e ter expectativas positivas em relação ao futuro, conforme pode ser verificado nas falas abaixo:

[...] Acredito que para termos uma boa qualidade de vida devemos ter boa saúde física e mental. Temos que fazer exercício para o corpo e a cabeça. Senão ficamos daqueles velhos cheios de doenças (Mulher, 73 anos). 
[...] Eu acho que a qualidade de vida começa quando a gente é jovem ainda. Tem que comer direito, fazer exercício, rir com os amigos e distrair a cabeça (Homem, 71 anos).

Assim, Ferreira et al. (2012) destacaram que, mesmo diante das perdas que naturalmente acontecem durante o processo de envelhecimento, deve-se priorizar o envelhecimento com qualidade de vida, relacionado com a manutenção da vida plena com saúde física e mental. Llobet et al. (2011) afirmaram que o conceito de qualidade de vida vem evoluindo. Possuía uma base materialista, onde os aspectos relacionados aos objetivos de vida eram prioridade; atualmente, os aspetos subjetivos são considerados essenciais. Estes autores destacaram que atualmente esta definição tem um caráter multidimensional, incluindo componentes objetivos e subjetivos. No tocante à subjetividade, trata-se de considerar a percepção do indivíduo sobre sua saúde e sobre os aspetos não médicos do seu contexto de vida. Quanto à objetividade, relaciona-se com indicadores socioeconômicos, como, por exemplo, renda e escolaridade (COSTA, 2011).

A Organização Mundial da Saúde (OMS) define qualidade de vida como: "A percepção que o indivíduo tem da sua posição na vida dentro do contexto da sua cultura e do seu sistema de valores, em relação aos seus objetivos, expectativas, padrões e preocupações" (ORGANIZAÇÃO MUNDIAL DA SAÚDE, 1995, p. 404).

Estudos de Llobet et al. (2011) sobre qualidade de vida indicaram que os idosos consideram importantes alguns fatores, como por exemplo: saúde, autonomia, fatores psicológicos (solidão, personalidade), ambiente adequado (habitação, ambiente social, serviços), fatores sociais (isolamento social), autoestima e dignidade, renda. Esses autores destacam que a percepção das pessoas idosas sobre a qualidade de vida não é má e muitas manifestam-se felizes e satisfeitas com a sua vida atual, conforme foi verificado na pesquisa.

Também Almeida, Gutierrez e Marques (2012) afirmam que "independentemente do conceito adotado e do instrumento utilizado sobre qualidade de vida, existe uma íntima relação entre esta, a saúde e a prática de exercícios físicos". Oliveira et al. (2010) citam que a prática de atividades físicas ajuda os idosos a se manterem saudáveis, aumentando a qualidade de vida à medida que envelhecem.

Quando perguntados sobre as atividades que mais gostam ou não gostam de realizar, os idosos destacaram, em sua grande maioria, atividades de lazer, pois como pode ser observado na figura 3 e nas falas transcritas, as pessoas idosas declararam palavras como: 
passear, dançar, forró, caminhar, corroborando às citações a respeito da manutenção da qualidade de vida, sobretudo em relação ao bem-estar físico e mental e a manutenção das redes sociais (figura 3):

[...] Eu gosto mesmo é de dançar um forró. Venho aqui (no PMTI) toda sexta. Não falto nunquinha. Também gosto de caminhar com minhas amigas. Faço isso todo santo dia (Mulher, 72 anos).

[...] Eu vou ao forró aqui (no PMTI) toda sexta. Vou em Teixeira toda quinta e vou em amparo do Serra quarta feira. Adoro dançar. É a melhor coisa da vida. Já sofri muito. Agora vou mesmo é aproveitar (Mulher, 80 anos).

[...] Ah minha fia. Por mim eu vivia passeano. Coisa que eu mais gosto de fazer é isso. Dançar também. Caminhar. Dar umas voltinhas. Isso é bom dimais (Mulher, 79 anos).

Figura 3 - Opinião dos entrevistados sobre o que mais gostam de fazer

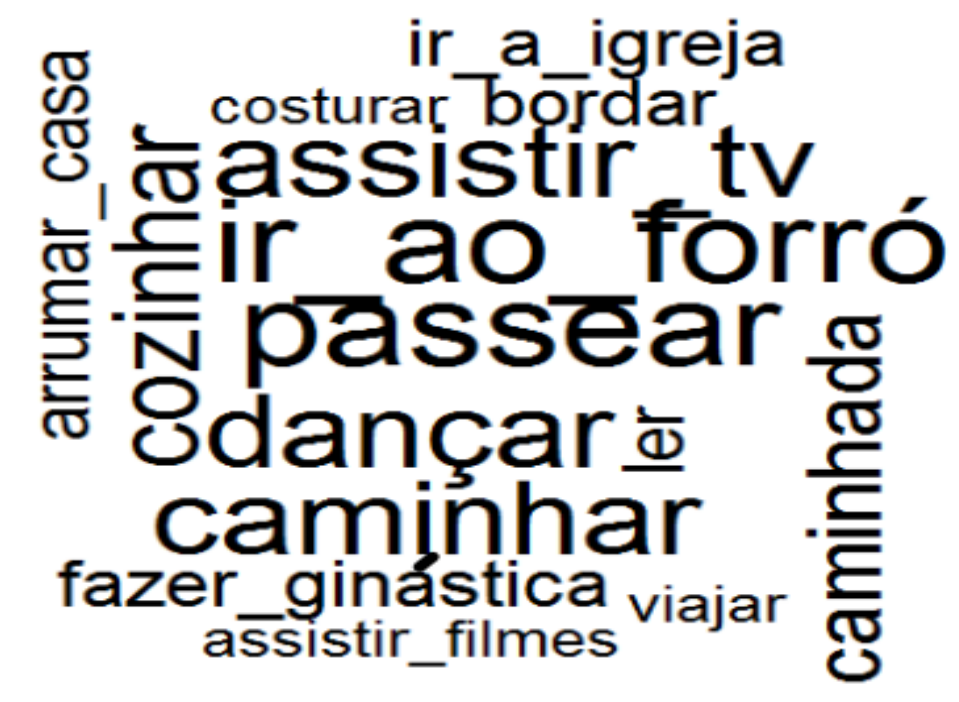

Fonte: Dados da pesquisa, 2018.

Em relação às atividades que os idosos não gostavam de realizar, as respostas mostraram que são atividades relacionadas ao cuidado da residência (figura 4), como: cozinhar e passar roupas. A satisfação que a maioria relatou ter nesta fase está ligada à possibilidade de fazer coisas que não podiam fazer antes, por causa de outras prioridades, como, por exemplo, cuidar da casa. Pode-se inferir que após passar grande parte do tempo cuidando de tarefas domésticas, os idosos preferem realizar atividades ao ar livre, destacando mais uma vez, a manutenção da qualidade de vida através do bem-estar físico e psicológico. 
Figura 4 - Opinião dos entrevistados sobre o que não gostam de fazer

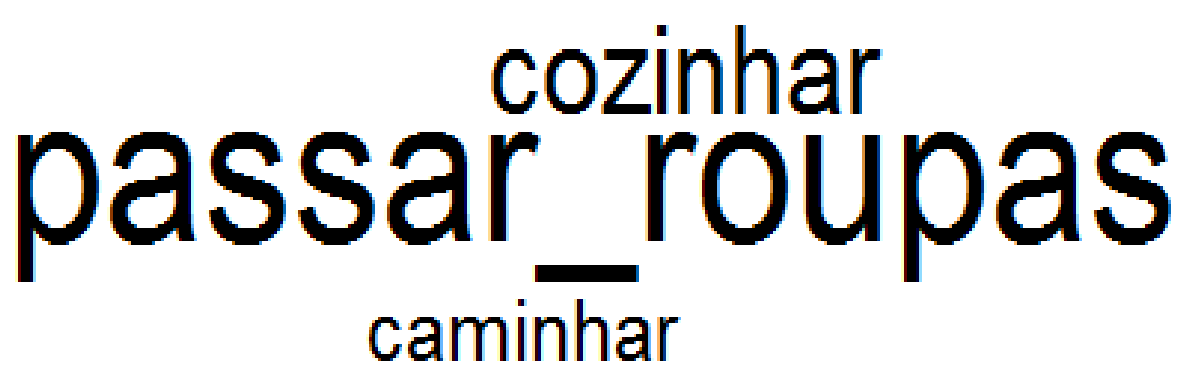

Fonte: Dados da pesquisa, 2018.

\section{Aspectos relacionados ao condomínio especializado para a pessoa idosa}

Para análise das respostas obtidas quando perguntado aos idosos participantes da pesquisa sobre a opinião acerca de um condomínio especializado para moradia da pessoa idosa, verificou-se a evocação das seguintes palavras: "muito boa", "boa ideia", "ótimo", "excelente", "ótima ideia" e "bom". Segundo eles, a ideia de um lugar para morar, com um grupo de pessoas de mesma faixa etária, que realizam atividades em grupo, além de assistência constante é uma ideia perfeita. Do total de entrevistados, apenas um afirmou que não moraria em um condomínio, visto que não gosta deste tipo de moradia. Assim, empregouse o método de "nuvem de palavras", que agrupa as palavras e as organiza graficamente em função da sua frequência e associação, apresentada na figura 5:

[...] Adorei essa ideia. Muito boa mesmo. O mais importante é a convivência e interatividade com outras pessoas da mesma idade. Parabéns (Mulher, 67 anos).

[...] Muito interessante. Excelente ideia. Perfeito. Nota 10. Melhor forma de se viver a velhice (Homem, 71 anos).

[...] Gostei muito. Perfeito para quem mora só. Maravilhoso. E ainda tem diversas atividades de recreação. Muito boa ideia (Mulher, 62 anos).

Figura 5 - Opinião dos entrevistados sobre a ideia do condomínio

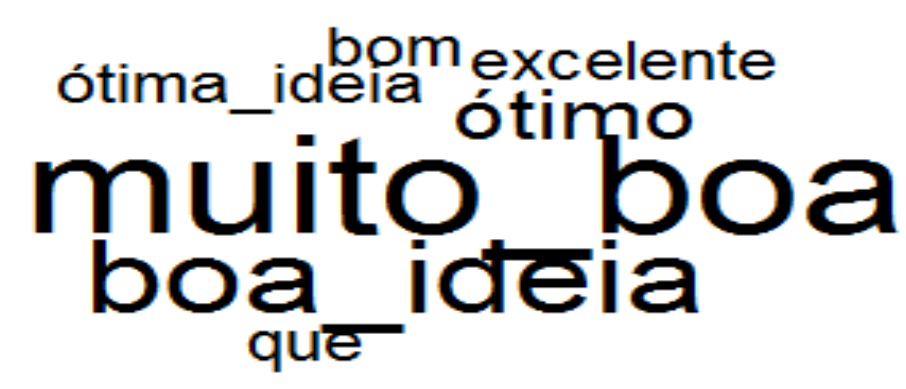

Fonte: Dados da Pesquisa, 2018. 
Em relação às respostas relativas aos questionamentos sobre o que se deveria existir nesse condomínio, tem-se as expressões: "academia", "centro de convivência", "ponto de ônibus", "horta comunitária", "salão de festas", "lazer" as que tiveram maior frequência no corpus.

Como as expressões "academia", "Centro de convivência", "salão de festas" e "horta comunitária", se destacaram entre a outras por serem espaços importantes de socialização para a pessoa idosa, buscou-se identificar seu contexto nas entrevistas. Eles enfatizaram que as expressões remetem a aspectos de lazer, considerado essencial as atividades do dia a dia. Também destacaram aspectos relacionados à qualidade de vida, realçando o aspecto da saúde física e mental. Verifica-se que na figura 6 as palavras estão dispostas de forma aleatória, porém destacando as que ocorrem com mais frequência, revelando seu destaque no corpus de análise da pesquisa.

[...] Tem que ter academia. Um salão de festas também. Acho que depois de trabalhar tantos anos, precisamos de um espaço pra diversão. Pra saúde ficar boa também (Homem, 78 anos).

[...] Eu acho bom ter uma hortinha. Pra gente plantar, né? Um espacinho pra ginástica também. Um lugarzinho pra gente dançar um pouco e conversar com os amigos (Mulher, 75 anos).

Figura 6 - Opinião dos entrevistados sobre o que deveria ter no condomínio

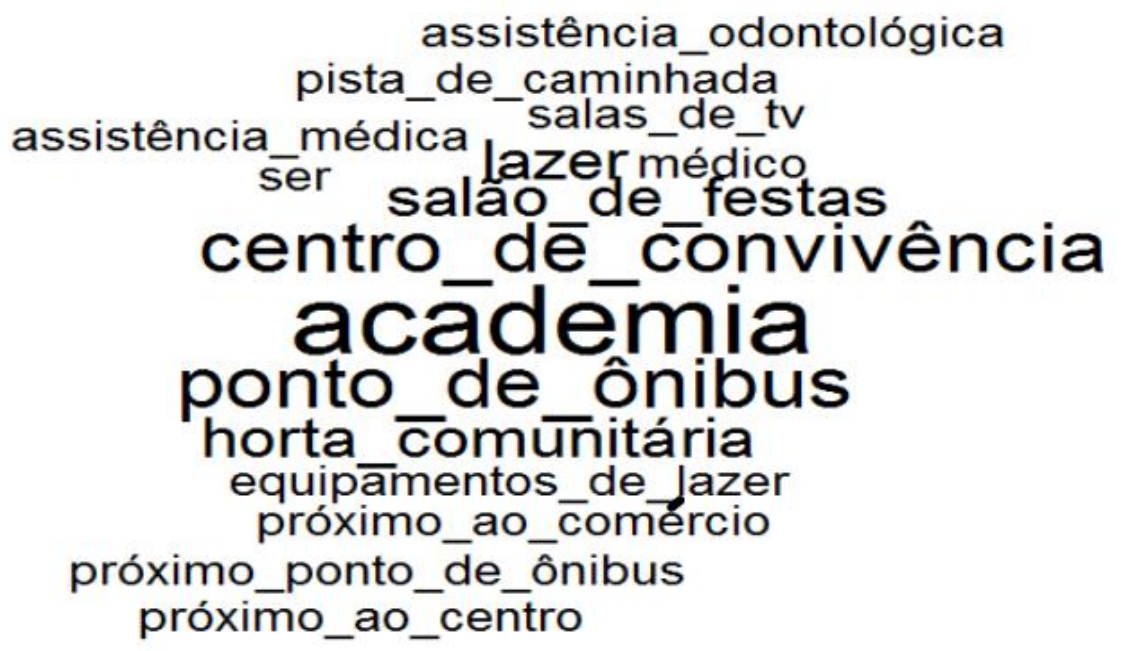

Fonte: Dados da Pesquisa, 2018.

Assim, pode-se inferir que os idosos estudados consideram que envelhecer em um lugar com pessoas de mesma idade, com rotinas familiares se traduz em satisfação e 
contentamento. Paúl (2005) reforça a importância do ambiente residencial na vida dos idosos, cuja satisfação com o lugar onde vivem está associada ao sentido de bem-estar entre eles.

Segundo Wister (1989), a casa, além de possuir a função de habitação, também contribui para a manutenção da saúde dos idosos. Segundo Silva et al. (2011), a casa significa mais do que somente um abrigo, cria laços de pertencimento e identidade em seu moradores e no condomínio. Pensamento corroborado por Proshansky, Fabian e Kaminoff (1983), que remetem à casa como sendo um ambiente seguro, permitindo a criação de raízes e o sentimento de pertença e identidade com o lugar. Assim, verifica- -se que essa é uma das razões pela qual a maioria dos idosos prefere permanecer em suas casas enquanto tiverem independência e autonomia (SABIA, 2008).

Petrella e Cres (2004) constataram que, embora exista uma preferência do idoso em envelhecer em sua moradia, isso muitas vezes não acontece, em virtude da redução de sua capacidade funcional, por causa das limitações em decorrência do próprio processo de envelhecimento que podem afetar sua autonomia e independência. Assim, quanto maior a situação de vulnerabilidade do idoso, maior atenção deve ser dada à dimensão física do ambiente residencial, reduzindo os obstáculos e incentivando a manutenção da independência da pessoa idosa, compensando suas limitações ou deficiências (STEINMAN, PYNOOS; NGUYEN, 2009), priorizando a qualidade de vida.

Pode-se verificar então, conforme Alves e Bassani (2005) que a relação pessoa idosa/ambiente contribui de forma significativa para o comportamento, percepções e emoções, assumindo um papel fundamental na manutenção da qualidade de vida e na construção da identidade do idoso.

Assim, verificou-se que os idosos preferem viver em casa, enquanto possuem autonomia. Wahl e Oswald, (2010) concluem que a satisfação com a moradia está ligada às características relacionadas à independência para em realizar as AVDs, assim como ao bemestar e percepção da qualidade de vida.

Então, a partir do objetivo proposto - avaliar a aceitabilidade de um grupo de idosos quanto a alternativa habitacional de moradia em condomínios especializados, adaptados à população idosa, verificou-se que a grande maioria dos entrevistados afirmou ser favorável a residir em um condomínio voltado a população idosa. Onde pudessem cultivar suas redes sociais através de atividades de lazer, com acesso aos serviços de saúde, podendo exercer sua cidadania, com a consciência de que a moradia adequada e seu entorno contribuem para um 
envelhecimento bem-sucedido, com autonomia e independência, proporcionando uma melhor qualidade de vida.

\section{Considerações finais}

Pôde-se concluir que a maioria dos idosos estudados (92,5\%) mostrou-se favorável a residir em um condomínio especializado, onde possam desfrutar da vida com independência e autonomia, realizando as atividades preferidas em companhia dos seus "iguais".

Assim, esta pesquisa buscou verificar, a partir da análise lexical, o que pensam os idosos de Viçosa a respeito de morar em um condomínio especialmente projetado para esse público peculiar. Dessa forma, a análise lexical se mostrou uma ferramenta importante para realização deste estudo, na medida em que evidenciaram no material coletado, palavras e expressões que demonstraram tal pensamento. $O$ software permitiu um olhar criterioso sobre o material coletado, qualificando o processo de categorização e, consequentemente, dos resultados do estudo, potencializando a pesquisa qualitativa.

Os dados referentes ao perfil da amostra foram úteis para a análise e compreensão das respostas, visto que a partir das características pessoais destacadas, foi possível entender o desejo de manutenção da saúde e a participação em atividades que auxiliem na promoção da mesma, considerando a autonomia e independência.

No tocante às palavras, tiveram maior frequência e associação entre si: "Saúde física" e "Saúde mental" considerando a importância da manutenção da saúde como forma de promoção e preservação da autonomia e independência durante o processo de envelhecimento, visto como um processo natural da vida humana; "Saúde", como elemento determinante de uma vida ativa e saudável. Deve-se destacar que o significado de qualidade de vida e envelhecimento saudável dado pelos entrevistados tem relação direta com o seu contexto e experiência de vida, tendo se destacado através dos aspectos ligados à manutenção de uma vida ativa, com atividades de lazer e convivência social.

Quanto às palavras "passear", "caminhar", "dançar", "forró", "TV" e "ginástica", verificou-se a importância dada às atividades de lazer e sociais, realizadas diariamente, também contribuindo para a manutenção da saúde e bem-estar. $E$ em relação às opiniões, sobre a moradia em condomínios, destaca-se que a satisfação encontrada revela a deficiência nas moradias atuais desses idosos, considerando que o ambiente residencial deve facilitar tanto as atividades cotidianas quanto às atividades sociais, considerando-se os microssistemas 
(quarto, sala, cozinha, área de serviços) e os macrossistemas (vizinhança, bairro, comunidade). Verificou-se que relações entre a pessoa idosa e o ambiente de moradia contribuem para que não existam barreiras para a independência e autonomia do idoso promovendo opções que facilitem o envelhecimento no local de moradia compensando as perdas funcionais dos idosos. Pode-se ressaltar a importância dos ambientes adaptados para promover e auxiliar a independência e autonomia, proporcionando uma boa qualidade de vida, conforme encontrado nas expressões em destaque na nuvem de palavras, dentre essas, pode-se citar: vida social, suporte familiar, saúde física e mental, religião, fé, atividades físicas, acessibilidade, boa moradia.

A pesquisa contribuiu para ampliar o estado da arte sobre moradia e envelhecimento, ao se discutir aspectos ligados ao processo de envelhecimento ativo com qualidade de vida para os idosos de Viçosa, assim como às questões relacionadas à manutenção da saúde física e mental, através de novas formas de "morar", visto que se constatou que cerca de $20 \%$ dos idosos de Viçosa moram sozinhos, o que reflete diretamente na configuração dos arranjos familiares. Essas mudanças têm implicações diretas no modo de morar da população idosa, e revelam que os condomínios especializados para esta população, devem compor não só as redes de assistência e de saúde, mas também a de habitação para esses idosos que ainda possuem autonomia para desempenhar as atividades da vida diária. Eles surgem como uma alternativa para se evitar ou retardar a necessidade de institucionalização do idoso.

\section{Referências}

ALMEIDA, Marco Antonio Bettine; GUTIERREZ, Gustavo Luis; MARQUES, Renato. Qualidade de vida: definição, conceitos e interfaces com outras áreas de pesquisa. São Paulo: Escola de Artes, Ciências e Humanidades - EACH/USP, 2012.

ALVES, Maria Cherubina de Lima, BASSANI, Marlise Aparecida. A psicologia ambiental como área de investigação da inter-relação pessoa-ambiente. 2005. Disponível em: http://legacy.unifacef.com.br/novo/publicacoes/Ilforum/Textos\%20EP/Marlise\%20e\%20Ma ria\%20Cherubina.pdf. Acesso em: 14 out. 2018.

ARANHA, Valmari Cristina. O trabalho com grupos. In: JACOB FILHO, Wilson (org.) Prática a caminho da senecultura. São Paulo: Atheneu, 2003.

ARIGONI, Luiza Beck; CECCON, Marília; DAMAZIO, Vera. Morar com mais independência e autonomia: uma reflexão sob a perspectiva do design. In: CONGRESSO BRASILEIRO DE PESQUISA E DESENVOLVIMENTO EM DESIGN, 12., 2016, Belo Horizonte. Anais [...]. Belo Horizonte: Blucher, 2016. 
ARRUDA, Luíza Amélia Corrêa. Histórico do clube da vovó. 2013. Disponível em: https://clubedavovo.wordpress.com /2013/09/01/histórico/. Acesso em: 1 out. 2018.

BESTETTI, Maria Luisa Trindade. Habitação para idosos: o trabalho do arquiteto, arquitetura e cidade. 2006. 184 f. Tese (Doutorado em Estruturas Ambientais Urbanas) - Faculdade de Arquitetura e Urbanismo, Universidade de São Paulo, São Paulo, 2006.

BRASIL. [Constituição (1988)]. Constituição da República Federativa do Brasil: texto constitucional promulgado em 5 de outubro de 1988, com as alterações adotadas pela emenda constitucional no 1/1992. Brasília: Câmara dos Deputados, 1992.

BRASIL. Conselho Nacional de Saúde. Resolução no 466, de 12 de dezembro de 2012. Aprova normas regulamentadoras de pesquisas envolvendo seres humanos. Brasília: Diário Oficial da União, 2013.

BRASIL. Lei no 10.741, de 1ํ de outubro de 2003. Dispõe sobre o Estatuto do Idoso e dá outras providências. Brasília, DF: Presidência da República, 2003. Disponível em: http://www.planalto.gov.br/ccivil_03/leis/2003//10.741.htm. Acesso em: 5 mar. 2018.

CAMARGO, Brigido Vizeu; JUSTO, Ana Maria. IRAMUTEQ: um software gratuito para análise de dados textuais. Temas em Psicologia, Ribeirão Preto, v. 21, n. 2, p. 513-518, 2013.

CAMARGOS, Mirela Castro Santos; MACHADO, Carla Jorge; RODRIGUES, Roberto do Nascimento. A relação entre renda e morar sozinho para idosos paulistanos - 2000. Revista Brasileira de Estudos de População, São Paulo, v. 24, n. 1, p. 37-51, jan./jun. 2007.

COSTA, Mayara. Qualidade de vida na terceira idade: a psicomotricidade como estratégia de educação em saúde. 2011, 150 f. Dissertação (Mestrado em Ciências da Educação) Universidade Lusófona de Humanidades e Tecnologias, Lisboa, 2011.

CRAS - Viçosa/MG. Histórico do programa municipal da terceira idade (PMTI). 2007. Disponível em: http://crasvicosa.blogspot.com.br/2010/08/pmti-realiza-festa-emhomenagem-aos.html. Acesso em: 11 set. 2018.

CRUZ, Tancredo Almada (coord.). Retrato social de Viçosa V. Viçosa, MG: CENSUS, 2014. 91p. CSIKSZENTMIHALYI, Mihaly; ROCHBERG-HALTON, Eugene. The meaning of things: domestic symbols and the self. Cambridge: Cambridge University Press, 1981.

DEBERT, Guita Grin. Envelhecimento e curso de vida. Revista Estudos Feministas, Florianópolis, v. 5, n. 1, 1997.

DEBERT, Guita Grin; SIMÕES, Júlio Assis. Envelhecimento e velhice na família contemporânea. In: FREITAS, Elizabete Viana (org.). Tratado de geriatria e gerontologia. 2. ed. Rio de Janeiro: Guanabara Koogan. 2006. p. 1368-1373.

DECLARAÇÃO UNIVERSAL DOS DIREITOS HUMANOS. Assembleia Geral das Nações Unidas em Paris. 10 dez. 1948. Disponível em: http://www.dudh.org.br/wpcontent/uploads/2014/12/dudh.pdf. Acesso em: 26 set. 2018. 
ELY, Vera Helena Moro Bins; DORNELES, Vera Goulart. Áreas livres acessíveis para idosos. Paisagem Ambiente: ensaios. São Paulo, n. 22, p. 299-308, 2006.

FERREIRA, Olívia Galvão Lucena; MACIEL, Silvana Carneiro; COSTA, Sônia Maria Gusmão; SILVA, Antonia Oliveira; MOREIRA, Maria Adelaide Silva Paredes. Envelhecimento ativo e sua relação com a independência funcional. Texto Contexto Enfermagem, Florianópolis, v. 21, n. 3, p. 513-8, 2012.

FREITAS, Larissa. Cidade Madura: blog especializado em políticas para perssoas da $3 \underline{a}$ idade destaca projetoo criado por RC. 2019. Disponível em:

https://www.polemicaparaiba.com.br/paraiba/cidade-madura-blog-especializado-empoliticas-para-pessoas-da-3a-idade-destaca-projeto-criado-por-rc/. Acesso em: 5 ago. 21019.

GILLEARD, Chris; HYDE, Martin; HIGGS, Paul F. D. The impact of age, place, aging in place, and attachment to place on the well-being of the over 50s in england. Research on Aging, Thousand Oaks, v. 29, n. 6, p. 590-605. 2007.

GOLDENBERG, Mirian. A arte de pesquisar: como fazer pesquisa qualitativa em ciências sociais. Rio de Janeiro: Record, 2015.

GREENFIELD, Emily; MARKS, Nadine. Formal volunteering as a protective factor for older adults' psychological well-being. Journal of Gerontology: social sciences, Washington, v. 59, n. 5, p. 258-64, 2004.

IBGE - INSTITUTO BRASILEIRO DE GEOGRAFIA E ESTATÍSTICA. Indicadores sociodemográficos e de saúde no Brasil. Rio de Janeiro: IBGE, 2009.

IBGE - INSTITUTO BRASILEIRO DE GEOGRAFIA E ESTATÍSTICA. Perfil dos municípios brasileiros. Rio de Janeiro: IBGE, 2012. Disponível em: http://goo.gl/LgU08M. Acesso em: 1 out. 2018.

IBGE - INSTITUTO BRASILEIRO DE GEOGRAFIA E ESTATÍSTICA. Perfil dos municípios brasileiros. Rio de Janeiro: IBGE, 2013. Disponível em: http://goo.gl/LgU08M. Acesso em: 1 out. 2018.

IBGE - INSTITUTO BRASILEIRO DE GEOGRAFIA E ESTATÍSTICA. Pesquisa nacional por amostra de domicílios (PNAD). Rio de Janeiro: IBGE, 2015. Disponível em: http://www.ibge.gov.br. Acesso em: 1 out. 2018.

IBGE - INSTITUTO BRASILEIRO DE GEOGRAFIA E ESTATÍSTICA. Sinopse do senso demográfico de 2010. Rio de Janeiro: IBGE, 2010.

LAWTON, Mortimer Powell. Competence, environmental press, and the adaptation of older people. In: LAWTON, Mortimer Powell.; WINDLEY, Paul Gordon; BYERTS, Thomas (ed.). Aging and the environment. New York: Springer, 1982. p. 33-59.

LAWTON, Mortimer Powell. The impact of the environment on aging and behavior. In: BIRREN, James; SCHAIE, K. Warner (ed.). Handbook of the psychology of aging. New York: Van Nostrand Reinhold, 1977. p. 276-301. 
LIMA, Mariuza Pelloso. Gerontologia educacional. Revista Kairós, São Paulo, v. 4, p. 109-121, 2001.

LLEWELLYN, Sue; NORTHCOTT, Deryl. The "singular view" in management case studies qualitative research in organizations and management. An International Journal, [S. I.], v. 2, n. 3, p. 194-207, 2007.

LLOBET, Montserrat Puig; ÁVILA, Nuria Rodríguez; FARRÀS, Jaume; CANUT, Maria Teresa Lluch. Quality of life, happiness and satisfaction with life of individuals 75 years old or older cared for by a home health care program. Revista Latino-Americana de Enfermagem, Ribeirão Preto, v. 19, n. 3, p. 467-475, 2011.

MAFRA, Simone. Faces do envelhecimento: como é envelhecer em Viçosa. Viçosa: Ed. UFV, 2014.

MARTIN, Ignacio; SANTINHA, Gonçalo; RITO, Susana; ALMEIDA, Rosa. Habitação para pessoas idosas: problemas e desafios em contexto português. Sociologia: revista da Faculdade de Letras da Universidade do Porto, Porto, p. 177-203, 2012.

MARTINS, Gilberto Andrade. Estudo de caso: uma reflexão sobre a aplicabilidade em pesquisas no Brasil. Revista de Contabilidade e Organizações, Ribeirão Preto, v. 2, n. 2, p. 918, 2008.

MELLIS, Fernando. Número de idosos no Brasil deve dobrar até 2042, diz IBGE. Disponível em: https://noticias.r7.com/brasil/numero-de-idosos-no-brasil-deve-dobrar-ate-2042-dizibge-25072018. Acesso em: 26 out. 2018.

MUELLER, Timothy I.; KOHN, Robert; LEVENTHAL, Nina; LEON, Andrew C.; SOLOMON, David; CORYELL, William; ENDICOTT, Jean; ALEXOPOULOS, George S.; KELLER, Martin. The course of depression in elderly patients. American Journal of Geriatric Psychiatry, Washington, v. 12, p. 22-29, 2004.

OLIVEIRA, Aldalan Cunha; OLIVEIRA, Núcia Macêdo Diniz; ARANTES, Paula Maria Machado; ALENCAR, Mariana Asmar. Qualidade de vida em idosos que praticam atividade física: uma revisão sistemática. Revista Brasileira de Geriatria Gerontologia, Rio de Janeiro, v. 13, n. 2, ago., 2010.

ORGANIZAÇÃO DAS NAÇÕES UNIDAS. Plano de ação internacional contra o envelhecimento, 2002. Tradução de Arlene Santos. Brasília: Secretaria Especial dos Direitos Humanos, 2003. (Série Institucional em Direitos Humanos, v. 1).

ORGANIZAÇÃO MUNDIAL DA SAÚDE (OMS). The World Health Organization Quality of Life Assessment (WHOQOL): position paper from the World Health Organization. Social Science and Medicine, Oxford, v. 41, n. 10, p.403-409, 1995.

OSWALD, Frank; WAHL, Hans-Werner. Housing and health in later life. Reviews of Environmental Health, Berlin, v. 19, n. 3-4, p. 223-252. 2004.

PAÚL, Constança. Envelhecimento e ambient. In: SOCZKA, Luís. (org.). Contextos humanos e psicologia ambiental. Lisboa: Fundação Calouste Gulbenkian, 2005. p. 247-268. 
PETRELLA, John K.; CRESS. M. Elaine. Daily ambulation activity and task performance in community dwelling older adults aged 63-71 years with preclinical disability. The Journals of Gerontology Series A Biological Sciences and Medical Sciences, Oxford, v. 59, n. 3, p. 264-7, 2004.

PRADO, Adriana Romeiro de Almeida; PERRACINI, Monica Rodrigues. A construção de ambientes favoráveis ao idoso. In: NERI, Anita Liberalesso (org.). Qualidade de vida na velhice: enfoque multidisciplinar. Campinas, SP: Alínea. 2011. (Coleção Velhice e Sociedade).

PROSHANSKY, Harold M.; FABIAN, Aabbe K.; KAMINOFF, Robert. Place-identity: physical world socialization of the self. Journal of Environmental Psychology, London, v. 3, n. 1, p. 5783, 1983.

ROSEL, Natalie. Aging in place: knowing where you are. International Journal of Aging and Human Development, Farmingdale, v. 57, p. 77-90, 2003.

SABIA, Joseph J. There's no place like home: a hazard model analysis of aging in place among older homeowners in the PSID. Research in Aging, Boston, v. 30, n. 1, p. 3-35, 2008.

SÂMIA, Carolina Olsson Folino. Cozinha funcional: analise do espaço e do usuário idoso. 2008. Dissertação (Mestrado em Design e Arquitetura) - Universidade de São Paulo, São Paulo, 2008.

SÃO PAULO. Portal Governo de São Paulo. Programa vila dignidade. 2016. Disponível em: http://www.cdhu.sp.gov.br/perguntas-frequentes/programa-vila-dignidade. Acesso em: 5 fev. 2019.

SCHUSSEL, Zulma das Graças Lucena. Os idosos e a habitação. Revista Kairós Gerontologia, São Paulo, v. 15, n. 8, p. 53-66, 2012.

SILVA, Luiza Wilma Santana; SANTOS, Rafaela Gomes; SQUARCINI, Camila Fabiana Rossi; SOUZA, Adriano Lopes; AZEVEDO, Marlúcio Pereira; BARBOSA, Frank Ney Monteiro. Perfil do estilo de vida e autoestima da pessoa idosa: perspectivas de um Programa de Treinamento Físico. Revista Kairós Gerontologia, São Paulo, v. 14, n. 3, p. 145-166, 2011.

STEINMAN, Bernard A.; PYNOOS, Jon; NGUYEN, Anna Q. D. Fall risk in older adults: the role of self-rated vision, home modification, and limb function. Journal of Aging and Health, Newbury, v. 21, n. 5, p. 655-676, 2009.

TAMAI, Silvia Affini Borsoi. Atividade de terapia ocupacional. In: JACOB FILHO, Wilson (org.). Prática a caminho da senecultura. Grupo de Assistência Multidisciplinar ao Idoso Ambulatorial (GAMIA). Hospital das Clínicas da Universidade de São Paulo. São Paulo: Atheneu, 2003.

WAHL, Hans-Werner; OSWALD, Frank. Environmental perspectives on aging. In: DANNEFER, Dale; PHILIPSON, Chris (org.). The sage handbook of social gerontology. London: SAGE Publications, 2010. p. 111-124.

WEBBER, Sandra.; PORTER, Michele.; MENEC, Verena. Mobility in older adults: a comprehensive framework. The Gerontologist, St. Louis, v. 50, n. 4, p. 443-450. 2010. 
WISTER, Andrew Victor. Environmental adaptation by persons in their later life. Research on Aging, Beverly Hills, v. 11, n. 3, p. 267-291, 1989.

YIN, Robert K. Estudo de caso: planejamento e métodos. 3. ed. Porto Alegre: Bookman, 2005.

Recebido em: 03/06/2019

Aceito em: 25/10/2019 